1. Evaluating the benefits of alternative leak detection

2

$\begin{array}{lccc}{ }_{3} \text { Martin Lavoie }^{1} & \text { Dave Risk }^{1} & \text { Liz O'Connell } & \\ & \text { Jack Johnson }^{2} & \text { Emmy Atherton }\end{array}$

$$
\text { programs }
$$

5 Affiliations:

${ }^{1}{ }^{1}$ St Francis Xavier University, Department of Earth Sciences, Antigonish Nova Scotia, CA

7 2Arolytics, 102 - 5677 Harris St., Halifax Nova Scotia, CA.

${ }_{8}^{3}$ Pembina Institute, Vancouver, British Columbia, CA.

9 *Correspondence to: martin21skifond@gmail.com 


\section{Abstract}

New technologies have the potential to reduce the cost of leak detection and repair (LDAR) for producers of all sizes through smart LDAR program design, the right combination of technologies, and by collaboration between producers within the same geographic area. This potential was examined in an extensive study by conducting multiple simulations using the Arolytics AROfemp model to evaluate the impact of alternative technologies on the cost and effectiveness of LDAR. In this study, AROfemp simulated 418 LDAR programs, each with 1500 Monte Carlo simulations to account for the random nature of methane leaks. Each simulation incorporated asset information of real producers in Alberta different combinations of methane detection technologies (truck, airplane, and drone), various survey timings, and different thresholds for triggering follow-up surveys with a gas imaging camera for leak localization before repair. Our results showed that alternative monitoring programs can reduce the cost of finding methane leaks compared to traditional LDAR programs. This is valid both for companies acting on their own and those collaborating to conduct alternative LDAR programs together. Cost reductions for alternative LDAR programs can, in some cases, exceed 50\%. However, results were strongly impacted by the choice of technology, facility type, as well as program design and logistics. For multi-producer collaborations, the logistics of follow-up surveys are important since alternative technology surveys can be much faster than traditional ground-based camera surveys. To avoid delays in leak localization and subsequent leak repairs, enough ground crews must be available and deployed in timely manner. Alternative LDAR has the potential to reduce costs and/or achieve deeper methane emission reductions for all producers but is not a one-size fits all solution, and programs that are successful for one producer cannot necessarily be replicated for others. Collaboration between small producers has potential to address these barriers. 


\section{Introduction}

Methane $\left(\mathrm{CH}_{4}\right)$ is a short-lived climate pollutant with a radiative heating potential $\sim 30 \mathrm{x}$ higher than that of carbon dioxide $\left(\mathrm{CO}_{2}\right)$ over a 100-year timespan. In Canada, almost half of anthropogenic $\mathrm{CH}_{4}$ emissions originate from wasteful gas leaks and vents at oil and gas production facilities [Environment and Canada, 2018]. New Canadian regulations require oil and gas $(\mathrm{O} \& \mathrm{G})$ producers to inspect and fix upstream wells and facilities for $\mathrm{CH}_{4}$ leaks. In addition to regulatory pressure, it is probable that company culture plays a significant role in how pro-active producers are mitigating their $\mathrm{CH}_{4}$ emissions.

Federal and provincial $\mathrm{CH}_{4}$ regulations in Canada prescribes the use of handheld sensors to detect leaks, which is a slow and labour-intensive process. However, the regulations also allow for flexibility in measurement approach. Sensor development has accelerated in recent years, and newer alternative $\mathrm{CH}_{4}$ measurement approaches can be substantially cheaper when used in so-called smart triage-based management programs that focus repair efforts on the largest emitting sites. Such programs are classified as "Alternative Fugitive Emissions Management Programs", or Alt-FEMPs. Industry adoption of Alt-FEMPs has been slow as producers lack awareness of achievable cost reductions, don't understand how to demonstrate efficacy, or know of the best technology options are.

Using frequent feedback from the Alberta Energy Regulator, Arolytics developed a simulation model to demonstrate Alt-FEMP efficacy and to define costs and emission abatement potential for various alternative leak detection and repair programs. Tailored specifically for industry, the model is the only one of its kind offered commercially. The Arolytics $\mathrm{CH}_{4}$ model predicts program performance under various leak detection and repair scenarios, and it uses an infrastructural asset portfolio, as well as parameters for various commercially available alternative measurement tools. The simulation model also outputs cost estimates, using a cost library populated with information from service providers or public sources. For more information on the modeling methods, please refer to the Supplemental Information. 
In early 2020 during the first months of Canadian regulation, the Alberta Energy Regulator approved several producer-led Alt-FEMP applications, the majority of which were backed by Arolytics simulation results to demonstrate efficacy [AER, 2021]. Modeling studies to-date shows that measurement costs can be reduced by an estimated $10-50 \%$ by incorporating alternative measurement tools, or said another way, $\mathrm{CH}_{4}$ could be cut more sharply based on current levels of expenditure (Personal Communications). Within the current economic environment, any cost saving to help industry comply with regulations is beneficial. Currently, however, primarily large, progressive companies have chosen to implement Alt-FEMPs. The benefits of Alt-FEMPs should extend to smaller producers and co-located producer consortia, but this remains to be seen.

\subsection{Objective and Scope of Work}

The Arolytics model ran thousands of simulations to estimate realistic fugitive emission management program outcomes that use alternative methodologies. We analyzed the model results for cost savings and $\mathrm{CH}_{4}$ reduction potential under a defined set of assumptions. We ran these simulations using producer infrastructure files of various companies and sizes, as well as geographical regions where multiple producers are co-located and could potentially benefit from sharing the measurement costs associated with their Alt-FEMPs. Arolytics conducted the simulations, and St.Francis Xavier University, and Pembina Institute analyzed the results. We expected to see that:

1. Incorporating screening technology into an Alt-FEMP can result in cost savings.

2. Larger $\mathrm{CH}_{4}$ abatement is possible at present-day costs.

3. Collaboration between companies will help decrease measurement costs.

This project aligns with the Alberta Methane Emission Program (AMEP), in which the provincial government allotted $\$ 17 \mathrm{M}$ to help remove the barriers for producers to implement 
Alt-FEMPs. It also aligns with $\$ 750 \mathrm{M}$ Emission Reduction Fund, which includes support for companies to comply with provincial and federal $\mathrm{CH}_{4}$ regulations.

\section{Methodology}

\subsection{Simulations}

The Arolytics field-based equivalency model is written in $\mathrm{R}$ programming language and is run on Amazon Elastic Compute Cloud (EC2). The model incorporates the attributes of realworld or theoretical oil and gas producing infrastructures, methane detection methodology capabilities and limitations, as well as region-specific information regarding methane leaks and repair practices.

To simulate a fugitive emissions program, the model must be parameterized with leak and repair information, as well as the design of the preferred leak detection campaigns. When the model runs, it first calculates the baseline methane emissions total, which is an estimate of the total methane emissions over a defined time period, before a leak detection and repair program is implemented. On each day of the simulation, leaks are probabilistically added to the oil and gas assets based on a pre-defined Leak Production Rate (LPR). A vent distribution profile is also considered. Next, leak detection campaigns are simulated by deploying methane detection methodologies at pre-specified assets (as determined by the campaign design). The detection limits and other characteristics of each leak detection methodology are taken into account to determine whether or not the leak would likely be detected in each scenario. Finally, repairs are simulated according to the pre-specified number of repairs that can occur per day. The results of the simulation include estimated annual methane emissions, estimated program costs, total number of simulated leaks, total number of simulated repairs, the length of each field campaign, and more. See Supplemental Information for complete methodology description. 


\subsection{Infrastructure and Producer Selection}

The model was used to show Alt-FEMP scenarios in two geographic regions of Alberta consisting of multiple oil and gas producers (Table 1). Seven producers were selected among the top-60 oil and gas producers in Canada, representing different producer sizes. Region 1 (Medicine Hat) was composed of two producers, and Region 2 (Slave Lake) of six producers, each with a different number of facilities. The facility count ranged from 55 to 562 facilities per producer. Producer \#1 was present in both regions.

Table 1: Producer and Facility counts for each Region.

\begin{tabular}{llr}
\hline AER region & Producers & Facility Count \\
\hline Medicine Hat & Producer 1 & 562 \\
Medicine Hat & Producer 2 & 439 \\
Slave Lake & Producer 3 & 132 \\
Slave Lake & Producer 1 & 202 \\
Slave Lake & Producer 4 & 63 \\
Slave Lake & Producer 5 & 55 \\
Slave Lake & Producer 6 & 56 \\
Slave Lake & Producer 7 & 111 \\
\hline
\end{tabular}

The infrastructure files were provided by IHS and included facility type, facility subtype, and location. Only active facilities that reported production in Petrinex in the past 12 months were considered since those are the only facilities subject to the current regulations. The frequency requirement of fugitive emissions surveys for each facility subtype is shown in Table 2 . 
Table 2: Frequency of fugitive emissions surveys facility sub-type code. Source: Table 4 in Directive 060 - AER. All compressor stations $(601,621)$ to require 3x/year inspection was chosen to ere on the side of caution.

\begin{tabular}{|c|c|c|}
\hline Equipment or facility type & Facility sub-type codes & Frequency \\
\hline Sweet gas plants & 401 & Triannually \\
\hline Compressor stations $(<0.01 \mathrm{~mol} / \mathrm{kmol} \mathrm{H} 2 \mathrm{~S}$ in inlet stream) & 601,621 & Triannually \\
\hline Liquid hydrocarbon storage tanks with vent gas control & NA & Triannually \\
\hline Produced water storage tanks with vent gas control & NA & Triannually \\
\hline Gas plants & $402,403,404,405$ & Annually \\
\hline Straddle and fractional plants & 406,407 & Annually \\
\hline Compressor stations $(>=0.01 \mathrm{~mol} / \mathrm{kmol} \mathrm{H} 2 \mathrm{~S}$ in inlet stream) & 601,621 & Annually \\
\hline Battery and associated satellite facilities & $311,321,322,331,341,342,344,345,361,362,363,364$ & Annually \\
\hline Custom treating facilities & 611,612 & Annually \\
\hline Terminals & 671,673 & Annually \\
\hline Injection/disposal facilities & $501,502,503,504,505,506,507$ & Annually \\
\hline
\end{tabular}

\subsection{Modeling programs}

Arolytics modelled six different types of fugitive emissions management programs on a one-year time scale for 7 different theoretical producers. The baseline program represents a scenario where no Leak Detection and Repair (LDAR) occurs. The only leak repairs that occur in the baseline program are those that are expected to happen naturally as part of regular operator maintenance activities. The default program consists of one to three OGI-based LDAR campaigns per year, reflecting Alberta's regulatory requirements for fugitive $\mathrm{CH}_{4}$ management (Table 3).

In addition, Arolytics modelled four different Alt-FEMP types individually (Truck 2x, Drone 2x, Aerial 2x, Aerial 1x_Truck 1x) for each theoretical producer, as well as for the two multiproducer regions in Medicine Hat and Slave Lake. The four different Alt-FEMPs involved various combinations and survey frequencies of aerial, truck, and drone methodologies (Table 
3). An anonymous survey sent to several producers to understand what technology categories to model. It was assumed that all alternative technologies would be used for screening, with OGI being used for follow-up at the top emitting sites to localize precise leak sources for repair. Follow-up was defined based on a percentage of total infrastructure. For example, if follow-up was defined as $20 \%$, then $20 \%$ of facilities with highest emission rates required follow-up with OGI.

Nine-follow-up combinations, as seen in Table 3, were simulated in order to obtain a range of possible scenarios, and to understand the impact the follow-up has on cost-effectiveness and emission reduction potential for Alt-FEMPs. The nine follow-up combinations applied to each Alt-FEMP resulted in 36 variations of Alt-FEMPs being modelled. In total, we modelled 38 programs for each individual producer (36 variations of the four Alt-FEMPs + the baseline program + the default program). We took the same approach for multi-producer regions; we modelled 38 programs for Slave Lake, and 38 programs for Medicine Hat. In total, this resulted in model results for 418 different FEMPs.

It was important to model many different combinations of follow-up percentages because the follow-up parameter has a significant impact on emissions. Only leaks that are followed up for localization can be repaired. Please note this project did not test the effectiveness of various Alt-FEMPs, rather it tested the performance of programs under the chosen assumptions. Numerous additional options for Alt-FEMPs exist that were not modelled in this study, including different technology categories and work practices.

Cost assumptions used in this modelling are estimates only, and do not reflect the costs of any one company or service provider. In order to cover a range of possible costs for each methodology, we modelled both a low and high cost scenario for each program and region. The low and high costs were defined by both public information, as well as discussions with service providers directly (Table 4). It is probable that service providers who offer $\mathrm{CH} 4$ detection services will change the prices of their services to respond to market fluctuations. 
Table 3: Description of each monitoring technology. Each program has nine variants.

\begin{tabular}{|c|c|}
\hline Monitoring Program & \\
\hline baseline & No campaign, natural repairs are happening \\
\hline default & 1st campaign $100 \%$ OGI; 2 nd campaign $100 \%$ OGI; 3rd campaign $100 \%$ OGI \\
\hline aerial1x_truck1x & 1st campaign $100 \%$ Aerial followed by $20 \%$ OGI; 2 nd campaign $100 \%$ Truck followed by $20 \%$ OGI \\
\hline aerial1x_truck1x & 1st campaign $100 \%$ Aerial followed by $50 \%$ OGI; 2 nd campaign $100 \%$ Truck followed by $20 \%$ OGI \\
\hline aeriallx_truck1x & 1st campaign $100 \%$ Aerial followed by $80 \%$ OGI; 2 nd campaign $100 \%$ Truck followed by $20 \%$ OGI \\
\hline aerial1x_truck1x & 1st campaign $100 \%$ Aerial followed by $20 \%$ OGI; 2 nd campaign $100 \%$ Truck followed by $50 \%$ OGI \\
\hline aeriallx_truck $1 x$ & 1st campaign $100 \%$ Aerial followed by $50 \%$ OGI; 2 nd campaign $100 \%$ Truck followed by $50 \%$ OGI \\
\hline aerial1x_truck1x & 1st campaign $100 \%$ Aerial followed by $80 \%$ OGI; 2 nd campaign $100 \%$ Truck followed by $50 \%$ OGI \\
\hline aerial1x_truck $1 \mathrm{x}$ & 1st campaign $100 \%$ Aerial followed by $20 \%$ OGI; 2 nd campaign $100 \%$ Truck followed by $80 \%$ OGI \\
\hline aerial1x_truck1x & 1st campaign $100 \%$ Aerial followed by $50 \%$ OGI; 2nd campaign $100 \%$ Truck followed by $80 \%$ OGI \\
\hline aerial1x_truck1x & 1st campaign $100 \%$ Aerial followed by $80 \%$ OGI; 2 nd campaign $100 \%$ Truck followed by $80 \%$ OGI \\
\hline aerial2x & 1st campaign $100 \%$ Aerial followed by $20 \%$ OGI; 2 nd campaign $100 \%$ Aerial followed by $20 \%$ OGI \\
\hline aerial2x & 1st campaign $100 \%$ Aerial followed by $50 \%$ OGI; 2 nd campaign $100 \%$ Aerial followed by $20 \%$ OGI \\
\hline aerial2x & 1st campaign $100 \%$ Aerial followed by $80 \%$ OGI; 2 nd campaign $100 \%$ Aerial followed by $20 \%$ OGI \\
\hline aerial2x & 1st campaign $100 \%$ Aerial followed by $20 \%$ OGI; 2 nd campaign $100 \%$ Aerial followed by $50 \%$ OGI \\
\hline aerial2x & 1st campaign $100 \%$ Aerial followed by $50 \%$ OGI; 2 nd campaign $100 \%$ Aerial followed by $50 \%$ OGI \\
\hline aerial2x & 1st campaign $100 \%$ Aerial followed by $80 \%$ OGI; 2 nd campaign $100 \%$ Aerial followed by $50 \%$ OGI \\
\hline aerial2x & 1st campaign $100 \%$ Aerial followed by $20 \%$ OGI; 2 nd campaign $100 \%$ Aerial followed by $80 \%$ OGI \\
\hline aerial2x & 1st campaign $100 \%$ Aerial followed by $50 \%$ OGI; 2 nd campaign $100 \%$ Aerial followed by $80 \%$ OGI \\
\hline aerial2x & 1st campaign $100 \%$ Aerial followed by $80 \%$ OGI; 2 nd campaign $100 \%$ Aerial followed by $80 \%$ OGI \\
\hline drone $2 \mathrm{x}$ & 1st campaign $100 \%$ Drone followed by $20 \%$ OGI; 2 nd campaign $100 \%$ Drone followed by $20 \%$ OGI \\
\hline drone $2 \mathrm{x}$ & 1st campaign $100 \%$ Drone followed by $50 \%$ OGI; 2 nd campaign $100 \%$ Drone followed by $20 \%$ OGI \\
\hline drone $2 \mathrm{x}$ & 1st campaign $100 \%$ Drone followed by $80 \%$ OGI; 2 nd campaign $100 \%$ Drone followed by $20 \%$ OGI \\
\hline drone $2 x$ & 1st campaign $100 \%$ Drone followed by $20 \%$ OGI; 2 nd campaign $100 \%$ Drone followed by $50 \%$ OGI \\
\hline drone $2 \mathrm{x}$ & 1st campaign $100 \%$ Drone followed by $50 \%$ OGI; 2nd campaign $100 \%$ Drone followed by $50 \%$ OGI \\
\hline drone $2 \mathrm{x}$ & 1st campaign $100 \%$ Drone followed by $80 \%$ OGI; 2 nd campaign $100 \%$ Drone followed by $50 \%$ OGI \\
\hline drone $2 \mathrm{x}$ & 1st campaign $100 \%$ Drone followed by $20 \%$ OGI; 2 nd campaign $100 \%$ Drone followed by $80 \%$ OGI \\
\hline drone $2 x$ & 1st campaign $100 \%$ Drone followed by $50 \%$ OGI; 2 nd campaign $100 \%$ Drone followed by $80 \%$ OGI \\
\hline drone $2 x$ & 1st campaign $100 \%$ Drone followed by $80 \%$ OGI; 2 nd campaign $100 \%$ Drone followed by $80 \%$ OGI \\
\hline truck2x & 1st campaign $100 \%$ Truck followed by $20 \%$ OGI; 2 nd campaign $100 \%$ Truck followed by $20 \%$ OGI \\
\hline truck $2 \mathrm{x}$ & 1st campaign $100 \%$ Truck followed by $50 \%$ OGI; 2nd campaign $100 \%$ Truck followed by $20 \%$ OGI \\
\hline $\operatorname{truck} 2 \mathrm{x}$ & 1st campaign $100 \%$ Truck followed by $80 \%$ OGI; 2nd campaign $100 \%$ Truck followed by $20 \%$ OGI \\
\hline truck $2 \mathrm{x}$ & 1st campaign $100 \%$ Truck followed by $20 \%$ OGI; 2 nd campaign $100 \%$ Truck followed by $50 \%$ OGI \\
\hline $\operatorname{truck} 2 \mathrm{x}$ & 1st campaign $100 \%$ Truck followed by $50 \%$ OGI; 2nd campaign $100 \%$ Truck followed by $50 \%$ OGI \\
\hline truck2x & 1st campaign $100 \%$ Truck followed by $80 \%$ OGI; 2nd campaign $100 \%$ Truck followed by $50 \%$ OGI \\
\hline $\operatorname{truck} 2 \mathrm{x}$ & 1st campaign $100 \%$ Truck followed by $20 \%$ OGI; 2 nd campaign $100 \%$ Truck followed by $80 \%$ OGI \\
\hline truck $2 \mathrm{x}$ & 1st campaign $100 \%$ Truck followed by $50 \%$ OGI; 2nd campaign $100 \%$ Truck followed by $80 \%$ OGI \\
\hline truck2x & 1st campaign $100 \%$ Truck followed by $80 \%$ OGI; 2nd campaign $100 \%$ Truck followed by $80 \%$ OGI \\
\hline
\end{tabular}


Table 4: Cost assumptions of each monitoring program and facility subtype.

\begin{tabular}{l|r|r}
\hline Technology & Cost/site - Low Cost Scenario (\$ CAD) & Cost/site- High Cost Scenario (\$ CAD) \\
\hline OGI - Sweet Gas Plant & $\$ 2,000$ & $\$ 3,120$ \\
\hline OGI - Compressor Station & $\$ 1,200$ & $\$ 2,500$ \\
\hline OGI - Gas Plant & $\$ 2,000$ & $\$ 3,120$ \\
\hline OGI - Straddle and Fractionation Plant & $\$ 2,000$ & $\$ 3,120$ \\
\hline OGI - Battery and Associated Satellite Facility & $\$ 600$ & $\$ 1,800$ \\
\hline OGI - Custom Treating Facility & $\$ 600$ & $\$ 1,800$ \\
\hline OGI - Terminal & $\$ 600$ & $\$ 1,800$ \\
\hline OGI - Injection/Disposal Facility & $\$ 600$ & $\$ 1,800$ \\
\hline Aerial & $\$ 130$ & $\$ 255$ \\
\hline Drone & $\$ 3,195$ & $\$ 3,835$ \\
\hline Truck & $\$ 2,700$ & $\$ 3,650$ \\
\hline
\end{tabular}

Therefore, we expect that these costs will vary from real-life scenarios and implementations of the programs modelled in this study. Multiple service providers offer OGI and alternative detection technologies at various prices, and this modelling was used as an exercise to test the impacts of different pricing assumptions.

\section{Results}

\subsection{Single-Producer Results}

Figure 1 shows that overall, modelled alternative programs resulted, on average $\sim 20 \%$ greater reduction in $\mathrm{CH}_{4}$ emissions (expressed in $\mathrm{CO}_{2}$ equivalent with a $\mathrm{GWP}$ of 34) compared to the default (existing regulatory) program. In the bottom panel, negative values indicate that the program will result in fewer emissions than the default program. With some variability among the program combinations and regions, the four alternative programs show a range of $-40 \%$ to $+60 \%$ emission reduction as compared to the default program. The two producers in Medicine Hat have more than 400 facilities each and they both show no reduction in $\mathrm{CH}_{4}$ emissions under default programs suggesting using the default program is favorable. The default program seems more advantageous in terms of dollar per $\mathrm{CO}_{2}$ equivalent reduced when the ratio of facilities that require $3 \mathrm{x}$ vs $1 \mathrm{x}$ annual surveying (i.e, $3 x: 1 x$ ratio) is over 0.15

(Figure 2). Both producers in Medicine Hat had a ratio over 0.15. There is no significant 
difference between the four alternative programs but Medicine Hat shows higher annual fugitive emissions per facility than Slave Lake.

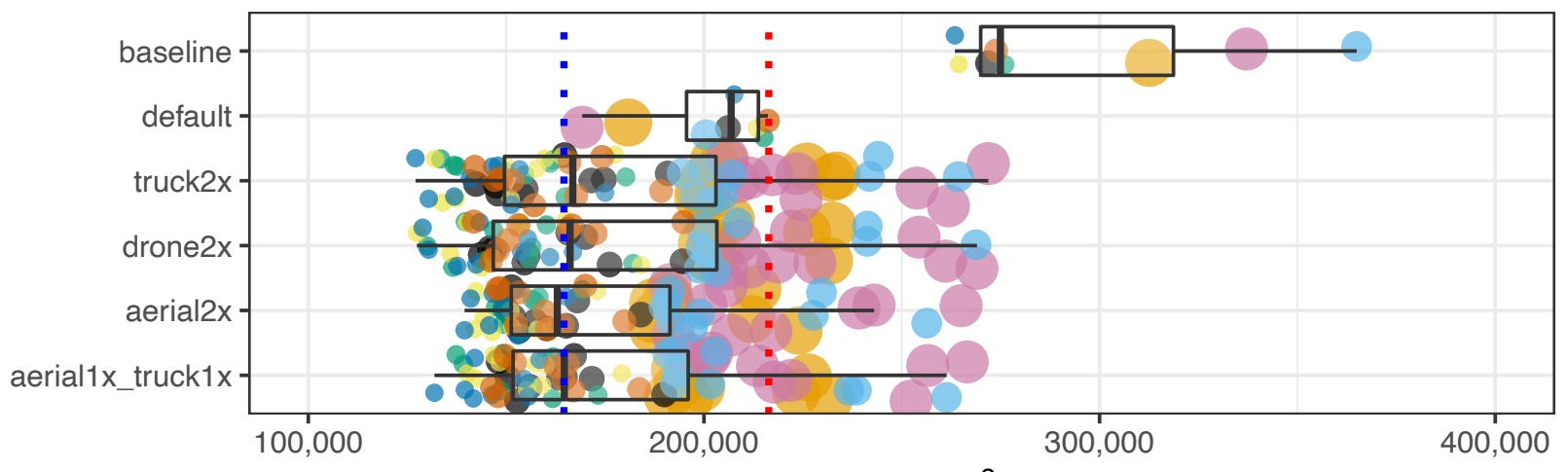

Annual Fugitive Emissions $\left(\mathrm{m}^{3} \mathrm{CO}_{2} \mathrm{E}\right)$ per Facility

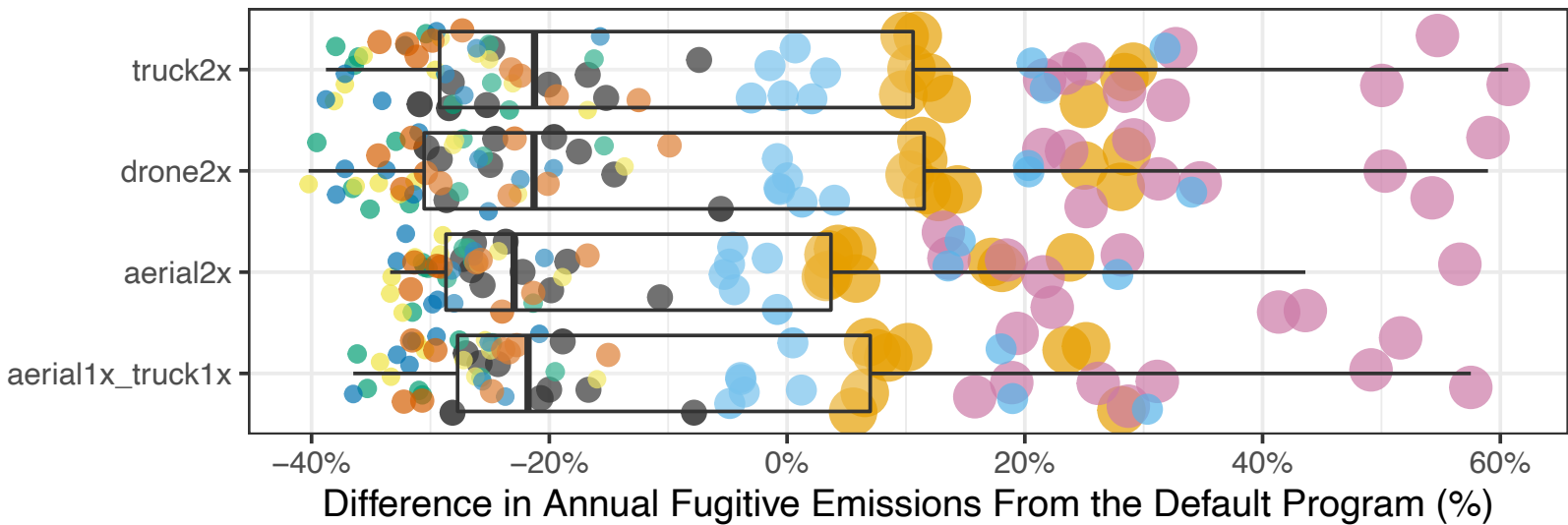

Figure 1: Annual fugitive $\mathrm{CH}_{4}$ emissions $\left(\mathrm{m}^{3} \mathrm{CO}_{2} \mathrm{E}\right)$ per facility (top panel) and difference in annual fugitive emissions from the default program (bottom panel) for different FEMP programs. Results from both Medicine Hat and Slave Lake are shown. Producers are represented by different colors and size in proportion to facility count. The boxplot shows the minimum (Q1- 1.5*IQR), first quartile (Q1), median, third quartile (Q3), and maximum $\left(\mathrm{Q} 3+1.5^{*} \mathrm{IQR}\right)$. Each producer has nine datapoints per Alt-FEMP, corresponding to a different amount of OGI follow-up after using alternative screening technologies. The blue dotted line represents the mean annual emission of the Alt-FEMP programs (excludes default) for the Slave Lake region, and the red dotted line indicates the mean annual emission of the Alt-FEMP programs for the Medicine Hat region.

For the low and high cost scenarios, average program cost for Alt-FEMP per facility is higher in Slave Lake than Medicine Hat where the producers have more facilities. Overall, the Aerial 2x and Aerial 1x_Truck 1x programs tend to have lower cost than the default program while the Drone 2x program was more expensive under the particular assumptions modelled. Percentage difference in cost from the default program was also highly variable with a range This paper is a non-peer reviewed preprint submitted to EarthArXiv 


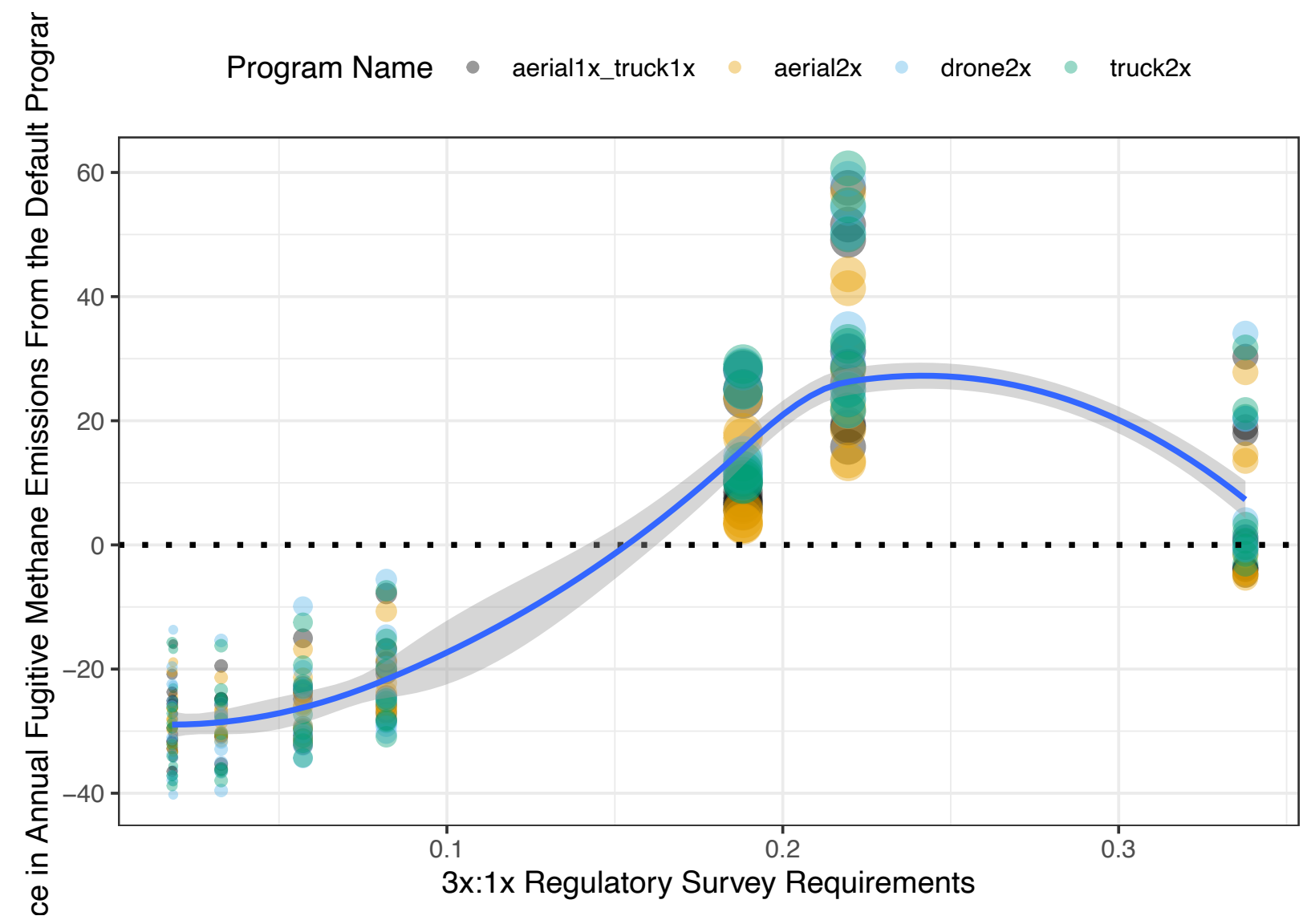

Figure 2: The relationship between $\mathrm{CH}_{4}$ emissions variance from the regulatory default program to the ratio of sites requiring $3 \mathrm{x}$ : $1 \mathrm{x}$ surveys per year according to Alberta regulatory requirements. Programs are represented by different colors and size is proportional to facility count. Each producer has nine datapoints per Alt-FEMP, each corresponding to a different amount of OGI follow-up after using alternative screening technologies. The black dotted line represents the default program. 
of $-70 \%$ to $+133 \%$ (Figure 3 ).
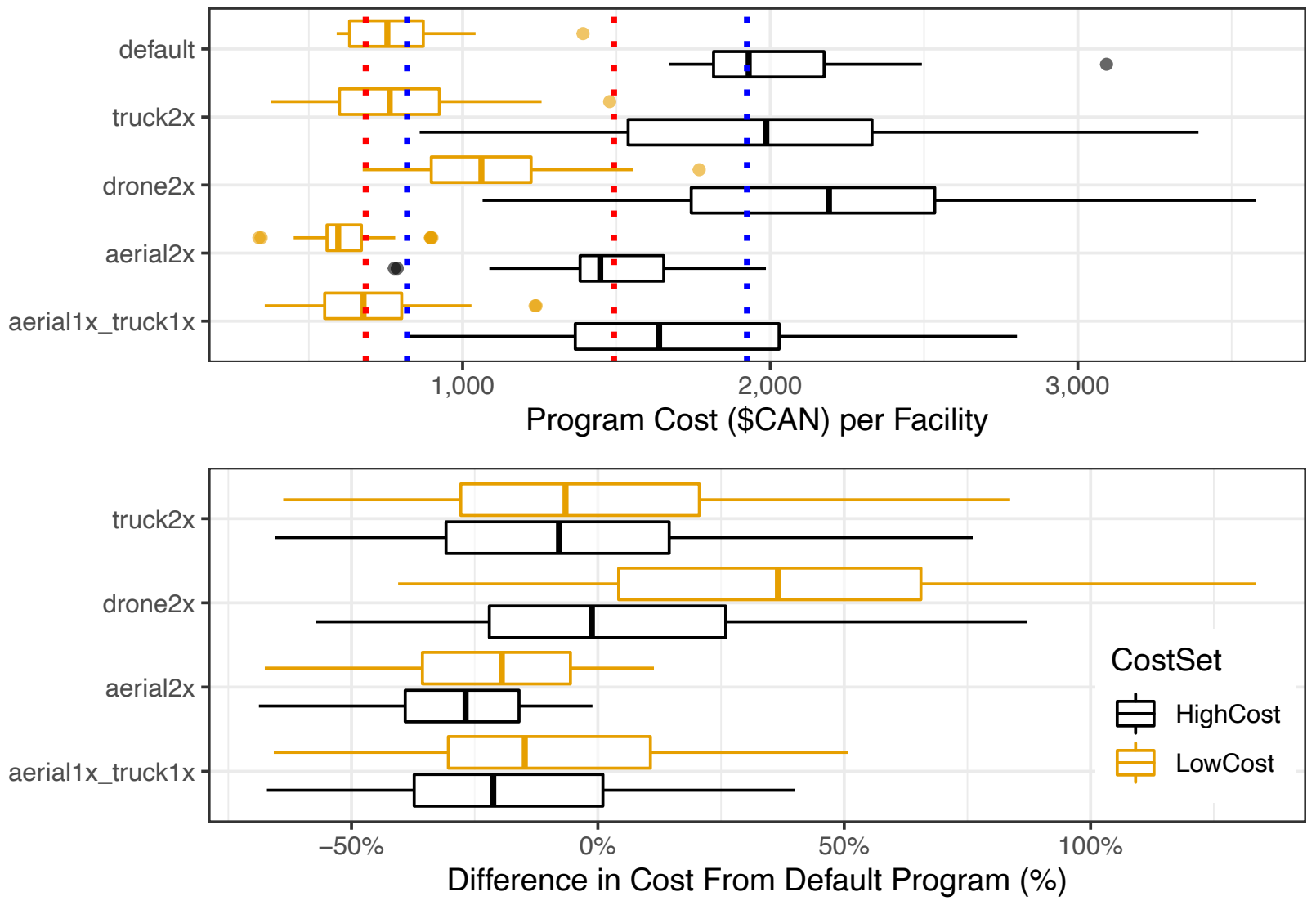

Figure 3: Program costs $(\$ C A N)$ per facility (top panel) and percentage difference in cost from default program (bottom panel) for each Alt-FEMP. Program costs include all screening and OGI leak localization campaigns. The boxplot shows the minimum (Q1- $1.5^{*} \mathrm{IQR}$ ), first quartile (Q1), median, third quartile (Q3), and maximum (Q3+1.5*IQR). The blue dotted lines represents the mean of the program cost $(\$ C A N)$ per facility of the Alt-FEMP programs (excludes default) for the Slave Lake region, and the red dotted lines for the Medicine Hat region.

In summary, for the low (Figure 4) and high (Figure 5) cost scenarios, most of the ninefollow-up combinations for the Truck 2x (5 for each scenario), Aerial 2x (9 for each scenario) and Aerial 1x_Truck 1x (7 and 6 respectively for each scenario) programs were successfully more economical and effective in reducing annual emissions than the default program. This is only valid for Slave Lake where producers have lower numbers of facilities.

This paper is a non-peer reviewed preprint submitted to EarthArXiv 


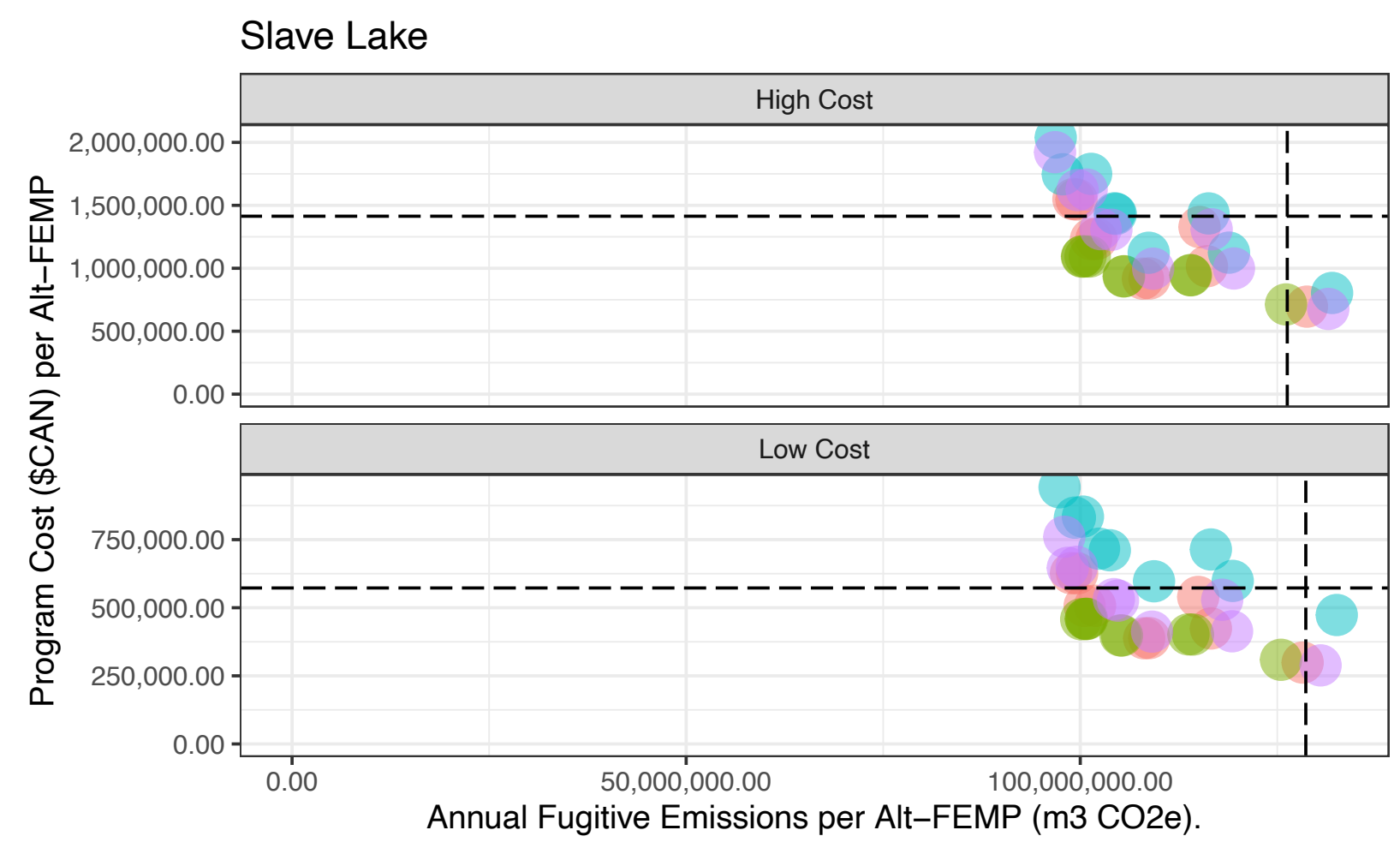

- aerial1x_truck1x $\odot$ aerial2x $\odot$ drone2x $\odot$ truck2x

Figure 4: Summary of program costs versus total fugitive $\mathrm{CH}_{4}$ emissions that result from each Alt-FEMP in the Slave Lake region (single-producer). Black dashed lines represent the estimated costs and emissions of the regulatory default program. Each Alt-FEMP is a different colour. There are nine datapoints per Alt-FEMP, each corresponding to a different amount of OGI follow-up after using alternative screening technologies. 


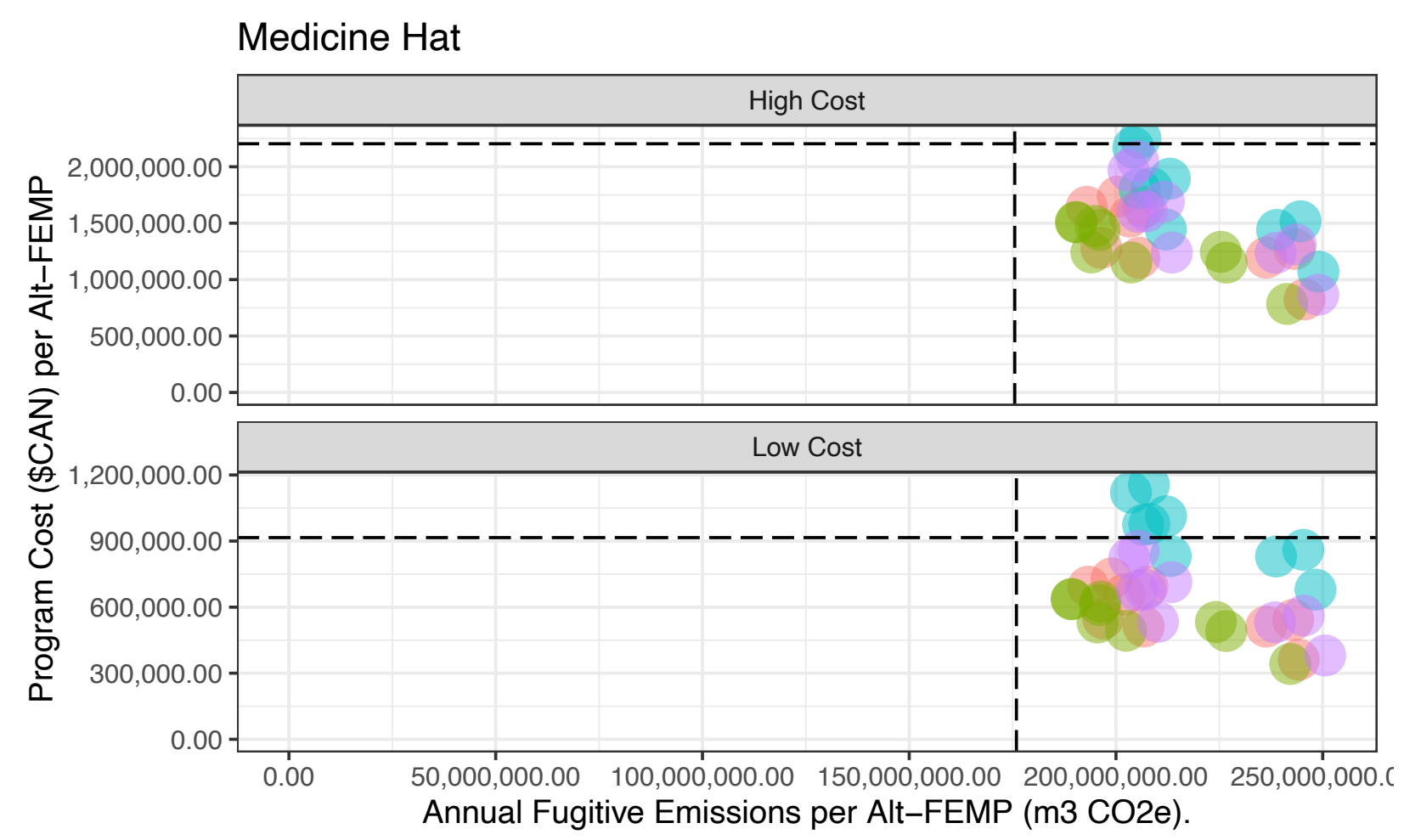

- aerial1x_truck1x $\odot$ aerial2x $\odot$ drone2x $\odot$ truck2x

Figure 5: Summary of program costs versus total fugitive $\mathrm{CH}_{4}$ emissions that result from each Alt-FEMP in the Medicine Hat region (single-producer). Black dashed lines represent the estimated costs and emissions of the regulatory default program. Each Alt-FEMP is a different colour. There are nine datapoints per Alt-FEMP, each corresponding to a different amount of OGI follow-up following alternative screening technologies.

This paper is a non-peer reviewed preprint submitted to EarthArXiv 


\subsection{Multi-Producer Results}

Single-producer results (mean $=190,000 \mathrm{~m}^{3} \mathrm{CO}_{2} \mathrm{E}$ ) show overall lower annual fugitive emissions per facility than multi-producer regions (mean $=213,000 \mathrm{~m}^{3} \mathrm{CO}_{2} \mathrm{E}$ ) with the exception of the default program (Figure 6). In the simulations, we assumed that all leak detection resources would be shared in multi-operator alt-FEMPs, including OGI services for leak localization following screening technologies. The results of the simulations showed that when leak detection services are shared between producers, it can result in a delay in the time required to localize leaks for repair. This was observed in the model results by follow-up campaigns starting later in the simulated year in multi-producer regions than they did in single producer regions. The delayed start date of follow-up campaigns in multiproducer regions resulted in leaks emitting for longer amounts of time before repair, therefore contributing higher overall emissions in multi-operator Alt-FEMPs. If the OGI services were not shared between companies, we estimate that the annual $\mathrm{CH} 4$ emission results between multi-operator and single operator programs would have been comparable. The difference in annual fugitive emissions from the default program is also more significant in Slave Lake than the multi-producer regions in Medicine Hat, which is primarily due to the $3 \mathrm{x}$ : $1 \mathrm{x}$ ratio differences (Figure 7).

As expected, program costs are lower when producers are working together especially in Medicine Hat where two large producers (> 400 facilities each) collaborated (data not shown). Although, due to high variability, it's difficult to infer specific patterns between Alt-FEMP programs for the low and high cost scenarios (Figure 9).

Although different program types under different assumptions were cost and emission reduction effective in Slave Lake, the Aerial 2x program had the greatest number of programs meet both of these criteria (Figure 8). 


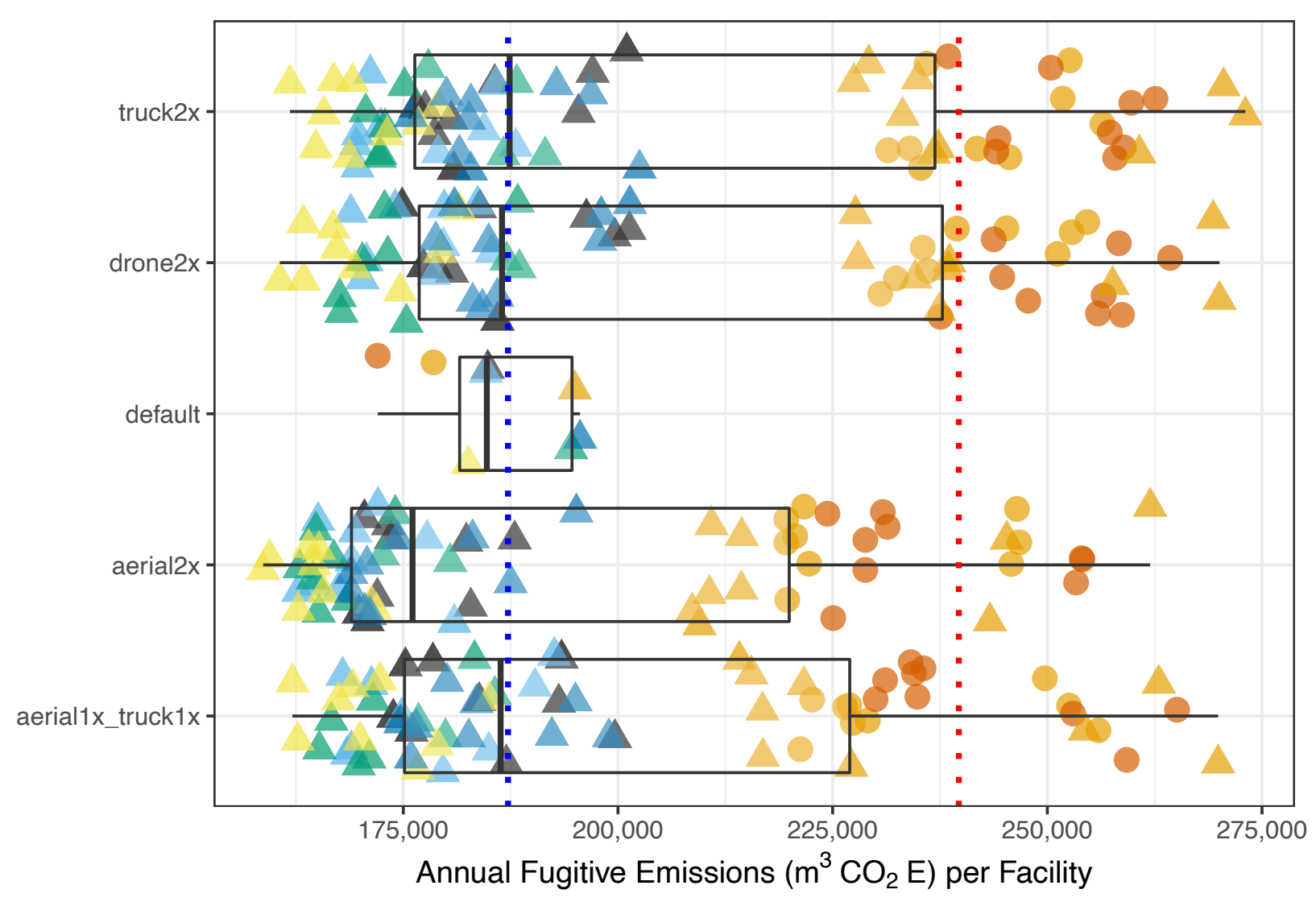

Figure 6: Annual fugitive $\mathrm{CH}_{4}$ emissions $\left(\mathrm{m}^{3} \mathrm{CO}_{2} \mathrm{E}\right)$ per facility (top panel) for different monitoring programs. Producers are represented by different colors, and shape represents AER areas (Slave Lake and Medicine Hat). The boxplot shows the minimum (Q1- 1.5*IQR), first quartile (Q1), median, third quartile (Q3), and maximum (Q3+1.5*IQR). Each producer has nine datapoints per Alt-FEMP, each corresponding to a different amount of OGI follow-up after using alternative screening technologies. The blue dotted line represents the mean annual emission of the Alt-FEMP programs (excludes default) for the Slave Lake region, and the red dotted line indicates the mean annual emission of the Alt-FEMP programs for the Medicine Hat region. 


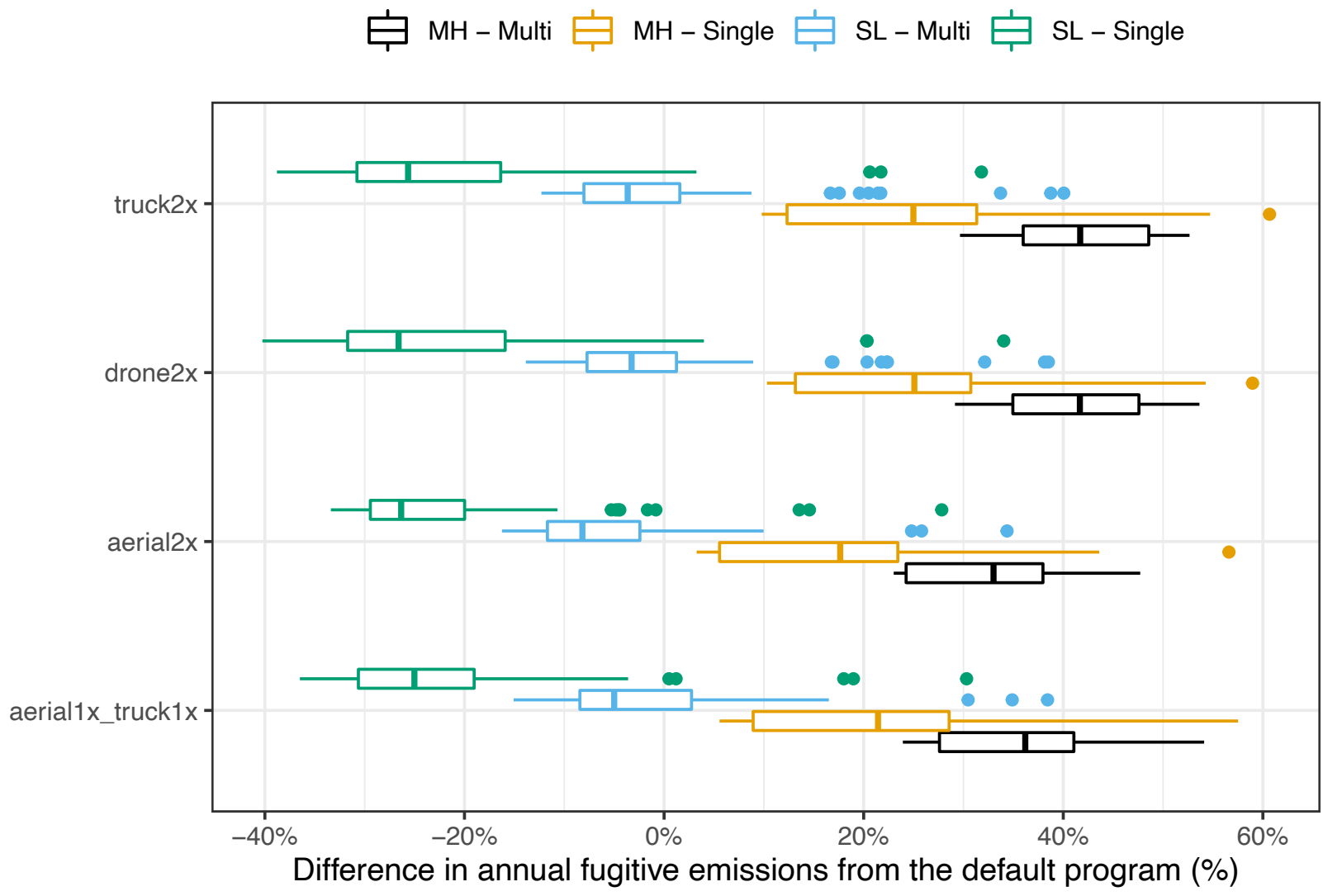

Figure 7: Difference in annual fugitive emissions from the default program for different monitoring programs. Multi-producer vs. single producers program types are represented by different colors. The boxplot shows the minimum (Q1- 1.5*IQR), first quartile (Q1), median, third quartile (Q3), and maximum (Q3+1.5*IQR). $\mathrm{MH}=$ Medicine Hat; $\mathrm{SL}=$ Slave Lake. 


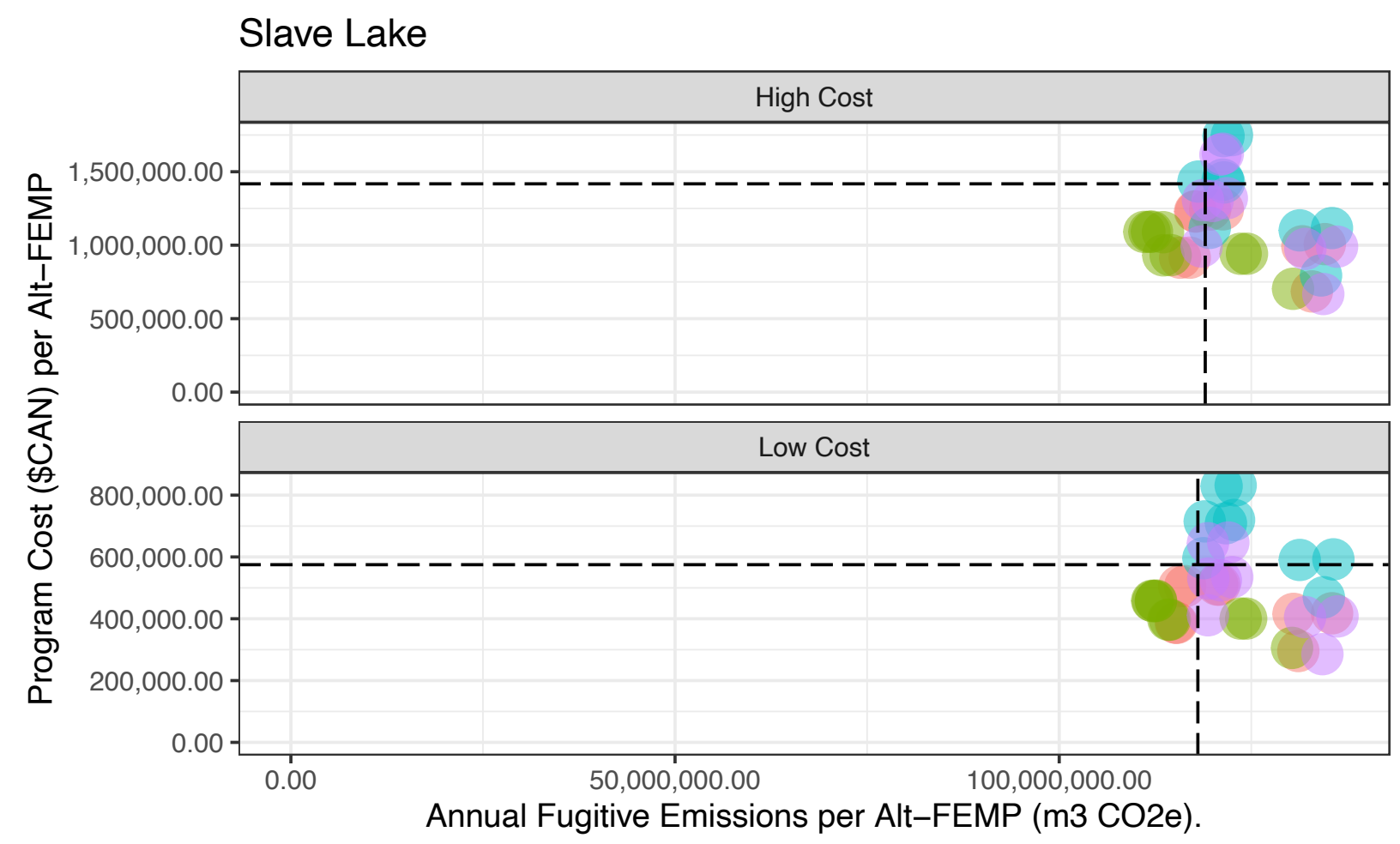

- aerial1x_truck1x ○ aerial2x ○ drone2x ○ truck2x

Figure 8: Summary of program costs versus total fugitive $\mathrm{CH}_{4}$ emissions that result from each Alt-FEMP in the Slave Lake region (multi-producer). Black dashed lines represent the estimated costs and emissions of the regulatory default program. Each Alt-FEMP is a different colour. There are nine datapoints per Alt-FEMP, each corresponding to a different amount of OGI follow-up after using alternative screening technologies. 


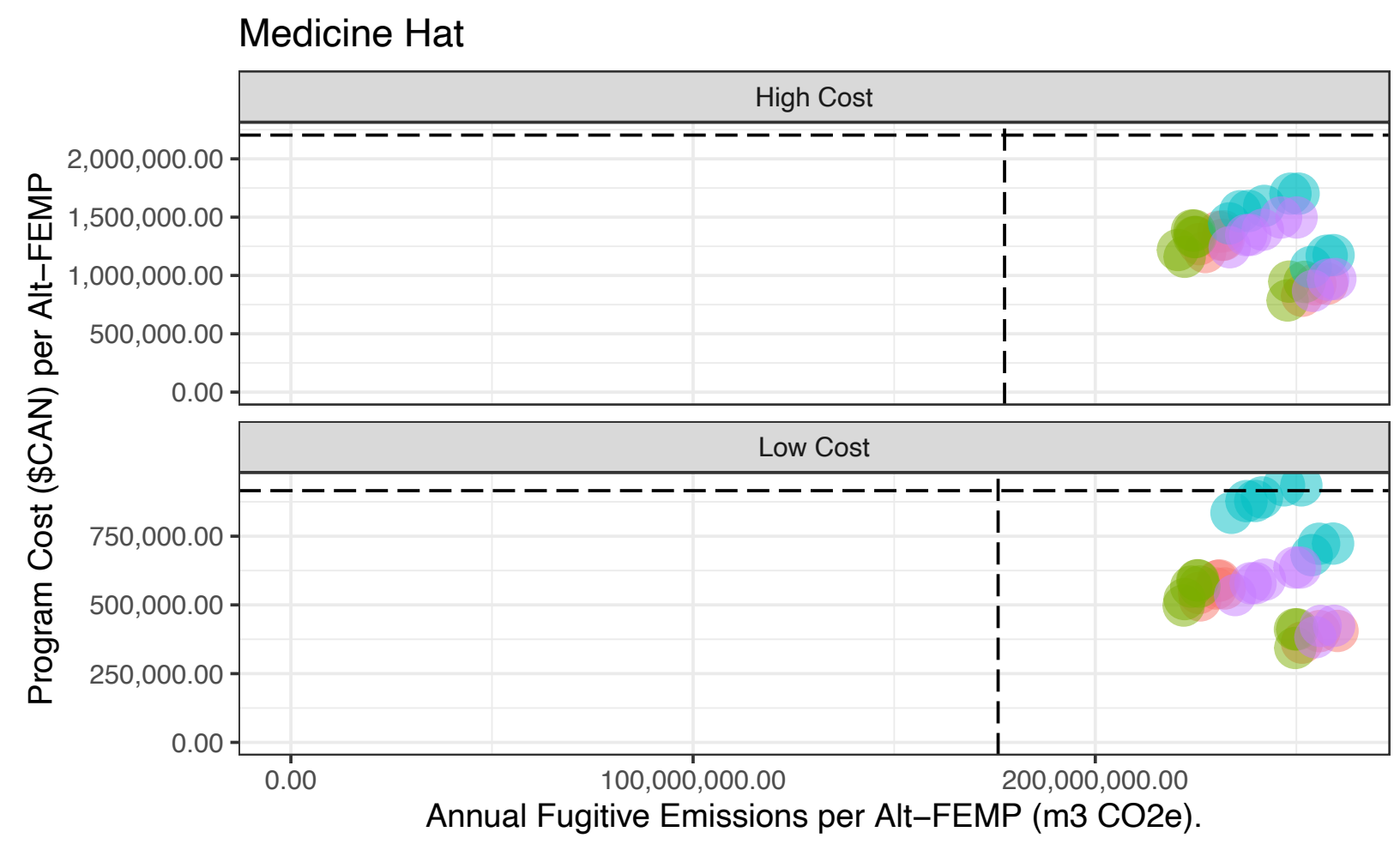

- aerial1x_truck1x $\odot$ aerial2x $\odot$ drone2x $\odot$ truck2x

Figure 9: Summary of program costs versus total fugitive $\mathrm{CH}_{4}$ emissions that result from each Alt-FEMP in the Medicine Hat region (multi-producer). Black dashed lines represent the estimated costs and emissions of the regulatory default program. Each Alt-FEMP is a different colour. There are nine datapoints per Alt-FEMP, each corresponding to a different amount of OGI follow-up after using alternative screening technologies. 


\section{Conclusion}

\subsection{Key Findings}

- Alternative monitoring programs can decrease costs of finding $\mathrm{CH}_{4}$ leaks compared to traditional LDAR programs. This is valid both for companies acting on their own and those collaborating to conduct alternative LDAR programs together. However, results are strongly impacted by alternate technology choices, program design, regional differences, and facility types.

- For multi producer collaborations, the speed and logistics of follow up surveys are important. Alternative technologies conduct surveys much faster than traditional ground-based camera surveys, but to capitalize on this speed adequate ground crews must be available to avoid delays in follow up.

- Additional benefits should be considered. Some technologies have the ability to quantify emissions at no incremental cost. Quantification including both fugitives and vented sources of $\mathrm{CH}_{4}$ emissions can help producers gain a better understanding of their operations and more effectively address $\mathrm{CH}_{4}$ emissions.

\subsection{Policy implications}

- Alternative LDAR is not a one-size fits all solution. Program design, technology choice, and facility types must be taken into account when designing alternative LDAR programs. This means that programs successful for one producer can not necessarily be replicated for others, and alternative programs may need to be tailored to a producers' or region's operations and facilities.

- If alternative LDAR programs prove successful, smaller producers, with limited resources, may be unable to undertake these programs. Collaboration between small producers could reduce barriers, but policies and support may be needed to level the playing field 
and provide equal access to smaller producers.

\section{Acknowledgements}

\section{${ }_{239}$ References}

We thank the McCall and MacBain Foundation for supporting this project.

AER. Alternative Fugitive Emission Management Program Approvals, 2021.

Environment and Climate Change Canada. National Inventory report 1990 - 2018: Greenhouse gas sources and sinks in Canada. Part 3, 2018. 


\author{
Martin Lavoie Dave Risk \\ Liz O'Connell \\ Emmy Atherton \\ Jack Johnson \\ Jan Gorski
}

\title{
4 Contents
}

S1 Sensitivity Tests

S2 Arolytics Model Description

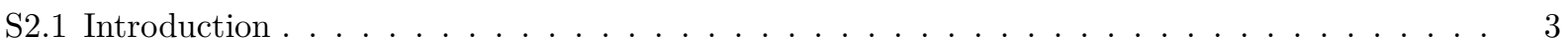

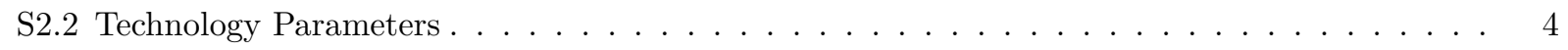

S2.3 Model Set-Up . . . . . . . . . . . . . . . . . . . . . . 6

S2.4 Input Parameters . . . . . . . . . . . . . . . . . . . . . . . . . . 8

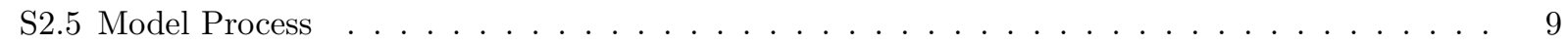

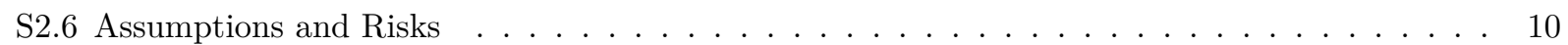

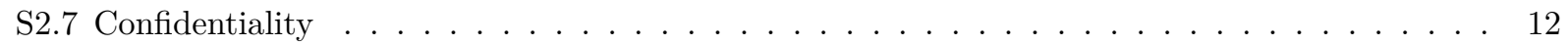

\section{S1 Sensitivity Tests}

In order to better understand the impact that certain assumptions had on the results of this study, we performed a sensitivity test on both the survey time (number of facilities per day that were surveyed) and survey costs (cost for each leak detection technology to survey one facility, or price per day).

Sensitivity to SurveyTime:

- Model estimates of total $\mathrm{CH}_{4}$ emissions are not directly sensitive to changes in the input survey times. Optimization/emission reduction improvement is possible when survey time is reduced as screening and follow-up campaigns are conducted faster, and therefore repairs occur sooner.

- Model estimates of total program costs are linearly and equally related (1:1) to changes in the input survey time values.

Sensitivity to Survey Cost:

- Model estimates of total $\mathrm{CH}_{4}$ emissions are not sensitive to changes in the input survey cost.

- Model estimates of total program costs are linearly and equally related (1:1) to changes in the input survey cost.

Below is the analysis of the model's sensitivity to the survey time input parameter. Three trials for two different regions were modelled.

Each trial included a default and a Truck 2x program: 
Table 1: Producer 8

\begin{tabular}{lrrrr}
\hline MP Run default-minus25_surveyTime & default-plus25_surveyTime & truck2x-minus25_surveyTime & truck2x-plus25_surveyTime \\
\hline Program Emissions \% Variance From Original & & & \\
1 & 0.1009189 & -0.8620387 & 0.1152797 & -0.4776247 \\
2 & & & -0.6539674 & -0.2267773 \\
3 & & 0.2867500 & 2.5374888 \\
4 & & -1.6202531 & -0.6279608 \\
5 & & -0.5152109 & -0.5524090 \\
6 & & -2.0751222 & 0.2522418 \\
7 & & 0.2952783 & -0.6030507 \\
8 & & -0.9261613 & -0.1485328 \\
9 & & 0.8332624 & 0.0955418 \\
AVG & 0.1009189 & -0.4733494 & 0.0276574 \\
Program Costs \% Variance From Original & -0.8620387 & & \\
1 & -25.0000670 & & & \\
2 & & & & \\
3 & & & -24.9362780 & 25.0545249 \\
4 & & -25.0136270 & 24.8948381 \\
5 & & -24.9266670 & 25.0154994 \\
6 & & -25.1082720 & 24.9576777 \\
7 & & -24.8905640 & 25.1181174 \\
8 & & -24.7172520 & 24.6208180 \\
9 & & -24.8262260 & 24.7194327 \\
AVG & & -24.9455070 & 24.7702811 \\
\end{tabular}

1. The survey time value as retrieved from literature/media (Default and Truck $2 \mathrm{x}$ programs).

2. The survey time value $+25 \%$ (Default and Truck $2 \mathrm{x}$ programs).

3 . The survey time value $-25 \%$ (Default and Truck $2 \mathrm{x}$ programs).

The sensitivity results suggest the following for both default and Truck $2 \mathrm{x}$ programs.

- Model estimates of total $\mathrm{CH}_{4}$ emissions are not very sensitive to changes in input survey time. This is true for both trial regions. The minimal emissions sensitivity observed is due to the ability to start follow-up campaigns a few days earlier (or later in the $+25 \%$ trials), in other words optimizing the program schedule for the new survey time. There appears to be no emissions sensitivity caused directly by the actual value of the input survey time parameter, rather they are only caused by optimizing the program schedule for the new survey time. To better understand the impact of optimizing program schedule, we modelled two regions with a $25 \%$ reduction in survey time, but only optimized the program schedule in one of the regions. The $25 \%$ survey time reduction yielded emissions reductions of less than $2 \%$ when optimized and less than $1 \%$ when not optimized. Therefore, even when optimizing for a reduced survey time, emissions are not significantly impacted by changes in survey time. Disclaimer: reducing and optimizing for survey time may in fact yield enough emissions reductions to push a program from non-equivalent to equivalent in terms of relative emissions reductions compared to default, though minor survey time improvements $(<25 \%)$ are not anticipated to be the best way to improve the estimated emissions reductions of a program.

- Outputted program costs are linearly related to input survey time. This is true for both regions. All programs with a $25 \%$ reduction in survey time yielded a $25 \%$ reduction in program cost. The same is true for a $25 \%$ increase in surveyTime.

These highlights are proven for both a default program and a Truck 2x (with followup 20, 50, 80\%) program, which means that these sensitivities can be applied to all current programs in this study.

The model's sensitivity to input survey costs is known to be linear and equal (1:1), as it is calculated in a simple multiplication of (surveys completed (screening and OGI follow-up) X survey costs). 
Table 2: Producer 4

\begin{tabular}{lcccc}
\hline MP Run default-minus25_surveyTime & default-plus25_surveyTime & truck2x-minus25_surveyTime & truck2x-plus25_surveyTime \\
\hline Program Emissions \% Variance From Original & & & \\
1 & 0.6622049 & -0.6711345 & -2.0151497 & 0.6883489 \\
2 & & & -2.2895771 & 2.7343596 \\
3 & & -1.9477399 & 1.2376829 \\
4 & & -2.6502121 & 0.7608943 \\
5 & & -1.9609274 & 2.7944524 \\
6 & & -2.4438401 & 0.8085315 \\
7 & & -0.3800098 & 2.3928534 \\
8 & & -1.8918858 & 2.7491064 \\
9 & & -2.4109563 & 0.9653201 \\
AVG & 0.6622049 & -1.9989220 & 1.6812833 \\
Program Costs \% Variance From Original & & & \\
1 & -24.9999692 & & & \\
2 & & & & \\
3 & & 24.9999692 & -24.8954729 & 24.8812805 \\
4 & & -24.7530043 & 24.8187525 \\
5 & & -24.7950728 & 24.6826313 \\
6 & & -24.9382677 & 24.8153649 \\
7 & & -24.7388380 & 24.3662361 \\
8 & & -24.8416897 & 24.6105092 \\
9 & & -24.9677211 & 24.8255698 \\
AVG & & -24.8914959 & 24.5871159 \\
\end{tabular}

\section{S2 Arolytics Model Description}

\section{S2.1 Introduction}

Arolytics has developed a methane emissions simulation model (the model) to estimate annual methane emission reductions that may result from implementing various Leak Detection and Repair (LDAR) programs. Arolytics has developed this model in response to Canadian federal and provincial methane regulations that came into effect in January 2020. These regulations require oil and gas producers to survey and/or screen qualifying wells and facilities for fugitive emissions (methane leaks) 1-3 times per year.

According to some provincial regulations, best practices for detecting fugitive emissions include Organic Vapour Analyzers and Gas-Imaging Cameras. In recent years, there has been a surge in research and innovation regarding alternative technologies for fugitive emissions detection and measurement. Examples of alternative technologies include satellites specialized for methane detection, aircraft-mounted gas sensors and imaging devices, drone applications, and ground-based vehicles outfitted with gas analyzers. These technologies have varying capabilities in terms of the magnitude of methane leaks they can detect, weather limitations, and the best practices required for optimal performance. For these reasons, regulators that accept some level of alternative technology use typically require oil and gas producers to submit applications for approval if they wish to deviate from what is prescribed as the default regulatory approach. Often, the applications must provide evidence that use of alternative methods will result in similar, or greater, emission reductions than the default approach.

The Arolytics field-based equivalency model is written in R programming language and is run on Amazon Elastic Compute Cloud (EC2). The model simulates methane leaks and repairs in regions that feature approximately uniform methods of upstream oil and gas production. The model incorporates the attributes of real-word oil and gas production infrastructure (wells and facilities), technology / service provider capabilities and limitations, as well as region and / or company-specific information regarding methane leaks and repair practices.

In order of preference, the Arolytics model uses methane emission and repair data from a) previous company leak detection data, b) the region to be modelled, or c) a nearby region with a similar oil and gas production style. As oil and gas producers begin conducting LDAR programs in 2020, increasingly large amounts of 
data will be available for defining model parameters. As new field data become available, model outputs will become more reflective of reality. By developing a model that uses real-world data, Arolytics' solution is uniquely positioned to be used by oil and gas producers in the future as routine LDAR programs take place across Canada. LDAR program features that can be adjusted and tested in the model include:

1. Using various detection or measurement technology types

2. Applying the technologies at various frequencies

3. Applying technologies to various combinations of infrastructure types

4. The order and timing in which technologies are implemented

5. The method of triggering "follow-up" technologies to help localize leaks after alternative technologies have detected methane at a site

6. The length of time between leak detection and repair

7. The time it takes each technology to survey the infrastructure involved

8. The effect of mitigating vented emissions in excess of regulatory requirements

Given the above, the user is able to model all possible combinations of parameters that form an LDAR program. The results from all modeled LDAR programs are organized by both the estimated cost to the producer and emission reduction potential. The Arolytics model does not assess the risk involved in implementing the proposed LDAR programs, as it is the sole responsibility of the producer to carry out the LDAR programs as prescribed.

\section{S2.1.1 Model Applications}

To-date, the Arolytics model has been used to support multiple alternative fugitive emissions management programs (Alt-FEMPs) to the Alberta Energy Regulator (AER) for large oil and gas producers. These applications of the model varied in terms of technology types, frequencies, methods for localizing leaks, and implementation of vent mitigation technologies. In each case, Arolytics modeled a baseline scenario (no LDAR), the implementation of a regulatory default LDAR program, and a variety of alternative LDAR programs.

Arolytics is also involved in research-oriented modeling projects to identify opportunities for Canadian producers to save measurement costs while achieving emission reductions in line with regulatory expectations by implementing alternative technologies.

\section{S2.1.2 Comparison to Other Techniques}

The Arolytics model is adaptable to a wide range of alternative LDAR programs, including all technology types, regulatory jurisdictions, and alternative approaches (such as varying measurement frequencies, followup thresholds for leak localizations, and measuring the impact of reducing vented emissions in excess of regulatory requirements). Arolytics is aware of other alternative LDAR program simulations, however we were approached in 2019 by oil and gas producers who were in need of a commercially-ready model. Since then, we have worked with industry to iterate on the model, allowing us to develop a tool that provides oil and gas producers and regulators with the answers they require to form methane management strategy.

We also recognized a gap in other models' ability to incorporate field-based, company-specific data. A key differentiator of the Arolytics model is its ability to integrate data that is local to the area being modeled. The parameters that fuel the Arolytics model are based upon the best available regional or company-specific data, providing a custom-tailored simulation for each unique application that will continuously improve as more LDAR data gets collected.

\section{S2.2 Technology Parameters}

Arolytics has researched and compiled information about relevant, commercial methane detection and measurement technologies. We have also consulted with service providers who specialize in implementing 
these technologies. Details about the capabilities, restrictions of use, and estimated costs of each technology have been compiled into a "Technology Parameters" file that is used as an input to the model.

Multiple industry, government, and academic initiatives have performed blind testing of various methane detection and measurement technologies in order to determine a) Minimum Detection Limits (MDLs), b) optimal operating conditions, c) the accuracy of measurement quantification, and d) the probability of detection. Where possible, Arolytics uses results from these studies to inform the parameters below.

Through our previous modeling work with Canadian oil and gas producers we have compiled an inventory of quotes and estimates that can be used in cases where specific technology information is not available.

\section{S2.2.1 Cost}

The model can incorporate technology cost as cost-per-day or cost-per-site (\$CAD). The costs incorporate all overhead and travel fees. To obtain these values, Arolytics contacts relevant service providers to obtain quotes to have their services deployed in the region or development of interest. It is important to obtain quotes specific to each area to be modeled because often the cost of services is dependent on the type or location of the development or spatial density of the infrastructure. If a producer chooses to internalize their LDAR program by purchasing a technology, the internal costs to the producer can be used instead.

Arolytics does not guarantee the accuracy of any cost estimates that result from the model because service providers have the flexibility to adjust costs at their own discretion. For each application of the model, Arolytics recommends that producers confirm the cost estimates by directly contacting service providers of interest.

\section{S2.2.2 Survey Time}

The amount of time it takes to survey a site is dependent on the technology type, its limitations, the service providers' work practices, the infrastructure types, and the spatial density of the development. For this reason, Arolytics consults with relevant service providers to obtain an estimate of the number of sites that can be surveyed or screened per working day in the region of interest. This approach removes the need for assumptions about travel times and/or work practices and provides the most accurate possible estimate of the length of time it will take to travel to and survey each site. In situations where this information cannot be obtained prior to running the model, the survey time is estimated based on previous survey time estimates from similar technology types and regions.

\section{S2.2.3 Minimum Detection Limit}

The Minimum Detection Limit (MDL) defines the smallest methane leak a technology is able to detect during normal operations. In order to incorporate an alternative technology into the model it is essential to have a well-defined MDL. Ideally, the MDL has been proven through both lab and field experimentations. If there has not been thorough testing completed, Arolytics will notify the producer of this information when providing model results.

For some technologies, the MDL can change depending on wind, temperature, cloud cover, etc. In these situations, we use the MDL that is suitable to average conditions for the region of interest at the time of year the technology is being implemented.

\section{S2.2.4 Measurement Scale}

Certain technologies for methane detection and measurement are better equipped to detect emissions at a site (well-pad) scale, while others are able to localize individual leak sources. It is important to consider this distinction in methodologies because it impacts a) the characteristics of the emissions that the technology 
will detect (ex. a site-scale technology might detect the cumulative sum of all leaks coming from a well-pad), and b) the actions that must follow a leak being detected (ex. whether or not the leak needs to be localized with a more precise technology before repair can take place).

The Arolytics model classifies technologies as either "site-scale" or "equipment-scale". This classification is based on both information provided by the service provider about the technologies' capabilities, as well as the producers' intended methodology for implementing the technology.

\section{S2.2.5 Probability of Detection}

The probability of detection defines the ability of a technology to detect methane leaks under normal operating conditions. For example, during blind tests. some technologies have been shown to only detect leaks at a certain percentage of known leaking sites, while others have detected methane at sites with no leaks (false positives). Arolytics consults with service providers to obtain and confirm this technology parameter. We also cross-reference values provided with any industry or academic studies that have been performed.

\section{S2.2.6 Other Restrictions}

Technology performance can be impacted by a variety of factors including wind speeds, temperatures, time of day, and cloud-cover. Certain technologies require specific combinations of these conditions in order to operate properly and achieve their reported MDL. After numerous conversations with both service providers and producers, it was determined that service providers do not typically operate in sub-optimal conditions, and the incorporation of "weather days" are normally included in quotes. For each application of the model, Arolytics confirms with service providers that the technologies will only be deployed in conditions that meet the technology performance requirements and that "weather days" will not impact measurement costs.

\section{S2.3 Model Set-Up}

Before running the model, the user must define an annual LDAR program as a series of methane measurement or detection "campaigns" (example in Table 1). Each campaign constitutes a technology being sent to a selection of upstream sites for leak detection. Typically, all infrastructure included in a campaign is only surveyed or screened once. If infrastructure needs to be surveyed more than once throughout the year, more campaigns are included in the LDAR program.

The LDAR program to be modeled can be adjusted to incorporate a variety of scenarios, including baseline (no LDAR), default (the regulatory default requirements for the region), or any type of alternative LDAR program.

\section{S2.3.1 Technology Type(s)}

The user can choose which technologies they wish to model from a list of technology options that Arolytics has compiled for the region of interest. Technology options include unique combinations of both the technology type and the service provider who will implement the technology. Each technology chosen to include in the program requires a new field measurement campaign, referred to as a "campaign".

\section{S2.3.2 Campaign Type}

For each campaign, the user must choose a "campaign type". Campaign types include: "survey", "flag", and "follow-up", defined below. 
Table 1: Example of a basic LDAR program design.

\begin{tabular}{|l|c|c|c|c|}
\hline Campaign & 1 & 2 & 3 & 4 \\
\hline Start Date & April 1st & June 1st & June 5th & September 1st \\
\hline Type & Survey & Flag & Follow-Up & Survey \\
\hline Technology & OGI & Aircraft & OGI & Truck \\
\hline Tech. Scale & Equipment & Site & Equipment & Site \\
\hline Infrastructure & All wells and & All wells and \\
facilities & $\begin{array}{c}\text { All sites from } \\
\text { Campaign 2 } \\
\text { found to be } \\
\text { emitting more } \\
\text { than 100 } \\
\mathrm{m}^{3} / \mathrm{day}\end{array}$ & $\begin{array}{c}\text { All single well } \\
\text { pads }\end{array}$ \\
\hline
\end{tabular}

Figure 1: Example of a basic LDAR program design.

- Survey: This campaign type signifies that the chosen technology is the main method of methane detection that will be used at each well or facility it is sent to. Infrastructure found to be emitting during a "survey" campaign will be repaired. Typically, OGI campaigns are classified as "survey" campaigns.

- Flag: This campaign type is typically chosen for "alternative" technology types that are unable to pin-point exact leak locations. A "flag" campaign indicates that any leaks identified with the chosen technology must be followed up by a more detailed technology to localize the leak and/or quantify the emission rate. Sites found to be emitting during a "flag" campaign will not be repaired until a "follow-up" campaign has taken place.

- Follow-Up: This campaign type is only used in conjunction with a "flag" campaign. During a "follow-up" campaign, the chosen technology is only sent to sites that were screened during the corresponding "flag" campaign and found to be emitting above a certain threshold (see Follow-Up Threshold below). Sites found to be emitting during a "follow-up" campaign will be repaired.

\section{S2.3.3 Campaign Infrastructure}

For each campaign, the user must define the specific infrastructure locations that will be surveyed, screened, or flagged. This approach provides the user with the flexibility to model more accurate LDAR programs. For example, some producers may want to experiment with using an alternative technology to identify leaks at more remote sites, while still implementing a default regulatory LDAR approach at sites with better accessibility.

\section{S2.3.4 Campaign Start Date}

The user must define a start date for each campaign. The model calculates the number of days each campaign will take according to the survey time defined for the technology (see Survey Time), and the infrastructure included in the current campaign (see Campaign Infrastructure). 


\section{S2.3.5 Follow-Up Threshold}

The follow-up threshold defines which sites identified as leaking during a "flag" campaign will be followed-up by a more detailed technology to localize the leak for repair. This threshold is either an emission rate (in $\mathrm{m} 3$ /day), or a portion of the highest emitting sites (for example, the $10 \%$ of sites found to be emitting the most). The follow-up threshold can be defined separately for each "flag" campaign included in the LDAR program.

\section{S2.4 Input Parameters}

Input parameters are compiled uniquely for each application of the model because each producer, geographical region, and production type are subject to varying methane emission characteristics.

Input parameters are most accurate for producers who have already conducted routine LDAR programs over multiple years, as these datasets provide insights into the producers' emission profiles and repair practices. As routine LDAR programs are conducted by all Canadian oil and gas producers throughout 2020, the rigor of the model input parameters will improve because real, and relevant, datasets can be used to calculate region and company-specific parameters.

\section{S2.4.1 Leak Production Rate}

The Leak Production Rate (LPR) is the probability that a given site will begin leaking on any given day. When possible, the LPR is calculated uniquely for each infrastructure type. In cases where a producer has already conducted routine LDAR programs, the LPR is derived from these datasets. In cases where there has been no rigorous LDAR programs to-date, the LPR is calculated from previous emission studies in similar areas and / or oil and gas development types.

The likelihood of leaks appearing or re-appearing, is an important characteristic to consider when modeling emission rates over time. To-date, LPR is loosely defined due to a lack of continuous and / or repeated methane measurements at upstream infrastructure. A key piece of missing data surrounding LPR is the reoccurrence of leaks at upstream infrastructure after they have been repaired. With each application of the model, Arolytics seeks to strengthen the validity of the LPR parameter using the new, and vast, amounts of LDAR measurements being collected in the Canadian oil and gas industry.

\section{S2.4.2 Leak Distribution Profile}

The Leak Distribution Profile (LDP) is a series of possible fugitive emission rates (in m3/day). The LDP defines the likelihood that various magnitudes of leaks might occur. When possible, we attempt to obtain a unique LDP for each infrastructure type, because often different infrastructure types have varying emission profiles.

In cases where a producer has already conducted routine LDAR programs, the LDP is derived from these datasets. In cases where there has been no rigorous LDAR programs to-date, the LDP is derived from previous emission studies in similar areas and / or oil and gas development types.

\section{S2.4.3 Repairs Per Day}

The model assumes that leaks may be repaired by the producer as soon as one day after they are detected. However, there is a limit to how many repairs a producer can reliably complete in one day. The number of repairs that can be performed in one day in the model is defined as "Repairs Per Day". This value is derived from conversations with producers about their operational practices. 


\section{S2.4.4 Natural Repair Rate}

Natural Repair Rate (NRR) is the probability that a leak will be repaired during normal operations, and not as a part of an LDAR program. The NRR is calculated from previous LDAR datasets when possible, or otherwise it is estimated from best available data. Typically, the NRR is low, and has negligible impact compared to other parameters.

\section{S2.5 Model Process}

This section defines each step of the methane simulation as it occurs in the model (example in Figure 1). The model is probabilistic because it incorporates random variables when simulating leaks, assigning leak sizes, and simulating repairs. This means that each time the model is run with the same input parameters it will produce different results. For this reason, a Monte Carlo simulation is used to approximate the most probable outcome.

\section{S2.5.1 Timestep}

The model typically simulates an LDAR program over a period of one calendar year (January 1st - December 31st), however longer simulations are possible. The model is run in a timestep of one day, which means that the process of simulating leaks and repairs is done on a day-by-day basis.

\section{S2.5.2 Campaign Length}

Using the infrastructure types, technology types, and corresponding survey time details (the number of sites that the service provider can survey in one working day), the model calculates the number of days required to complete each campaign. The campaign length is added to the campaign start date (defined during the model set-up) to provide a campaign end date. The campaign length does not incorporate weather days, as inclusion of weather days would not notably impact emission reductions or measurement costs. Campaign length is a key component to estimating LDAR program cost.

\section{S2.5.3 Leak Simulation}

For each day of the simulation, certain non-leaking infrastructure is randomly assigned a "leaking" status based on the LPR. The "leaking" status persists through every day of the simulation until the leak gets repaired (either naturally, or as part of the LDAR program). Each piece of infrastructure with a "leaking" status is randomly assigned an emission rate from the corresponding LDP.

Producers do not typically have comprehensive information about equipment located on each site, so leaks are simulated at the infrastructure (ex. well or facility) scale.

\section{S2.5.4 Campaign Simulation}

If the current day of the model is part of a campaign (as defined in Campaign Length), the model simulates the campaign leak detection activities. To do this, infrastructure locations are randomly selected to be surveyed or screened by the technology of the current campaign. The model randomly selects one piece of infrastructure at a time until the total time required to survey or screen those sites approximates one day. Once the sites to be surveyed on the current day are selected, the probability of leak detection is applied to identify where leaks might actually be detected. Finally, of the sites where leaks might be detected, if the selected infrastructure is leaking at an emission rate greater than the MDL of the technology being used in the campaign, the infrastructure is flagged as follows: 
- For "survey" campaigns: Infrastructure that are selected for the current day are identified as "surveyed", and infrastructure that are found to be leaking above the MDL are identified as "detected".

- For "flag" campaigns: Infrastructure that are selected for the current day are identified as "visited", and infrastructure that are found to be leaking above the MDL and the follow-up threshold are identified as "requiring follow-up".

- For "follow-up" campaigns: Infrastructure that are selected for the current day are identified as "surveyed", and infrastructure found to be leaking above the technology MDL are tagged as "detected".

This process is completed for each day of the year that has an active LDAR campaign.

\section{S2.5.5 Natural Repair Simulation}

To simulate natural repairs, leaking infrastructure are randomly selected to be repaired according to the NRR.

Directly after natural repairs, these infrastructure locations are no longer considered leaking for the current day. However, on the following day of the simulation, the newly repaired site is just as at risk of starting to leak as all other non-leaking sites. This process could change as we collect more comprehensive data about the probability of leaks reoccurring at various sites.

\section{S2.5.6 Repair Simulation}

For each day of the simulation, leaking infrastructure that has been detected on a "survey" or "follow-up" campaign can be repaired. To simulate repairs that are part of the LDAR program, all leaking infrastructure that was detected on a campaign is randomly selected until the maximum number of repairs per day has been reached. All leaks at the selected infrastructure locations are then repaired.

Directly after repairs, these infrastructure locations are no longer considered leaking for the current day. However, on the following day of the simulation, the newly repaired site is just as at risk of starting to leak as all other non-leaking sites. This process could change as we collect more comprehensive data about the probability of leaks reoccurring at various sites.

\section{S2.5.7 Results}

Results of the model include: (a) a day-by-day summary of estimated fugitive methane emission totals for the region, (b) the estimated cost of the modeled LDAR programs, (c) a summary of baseline emission calculations for the region and a comparison between baseline and alternative programs, and (d) a summary of emission reductions that would occur from implementing a default LDAR program for corresponding regulatory jurisdiction, and a comparison between default regulatory programs and alternative programs.

The model can be used to iteratively test combinations of various input parameters mentioned above. For example, the user may wish to test various follow-up thresholds with technology types. In this case, the model runs every possible combination of parameters and produces a summary of the most effective programs.

\section{S2.6 Assumptions and Risks}

It should be noted that results of the model are not guaranteed to reflect what may occur when these LDAR programs are implemented in reality. It is the sole responsibility of the producer to ensure LDAR programs are completed as prescribed. Arolytics has no control over the implementation of any proposed LDAR programs, and therefore does not guarantee that the LDAR program will result in methane emission reductions equivalent to or less than default LDAR programs. 


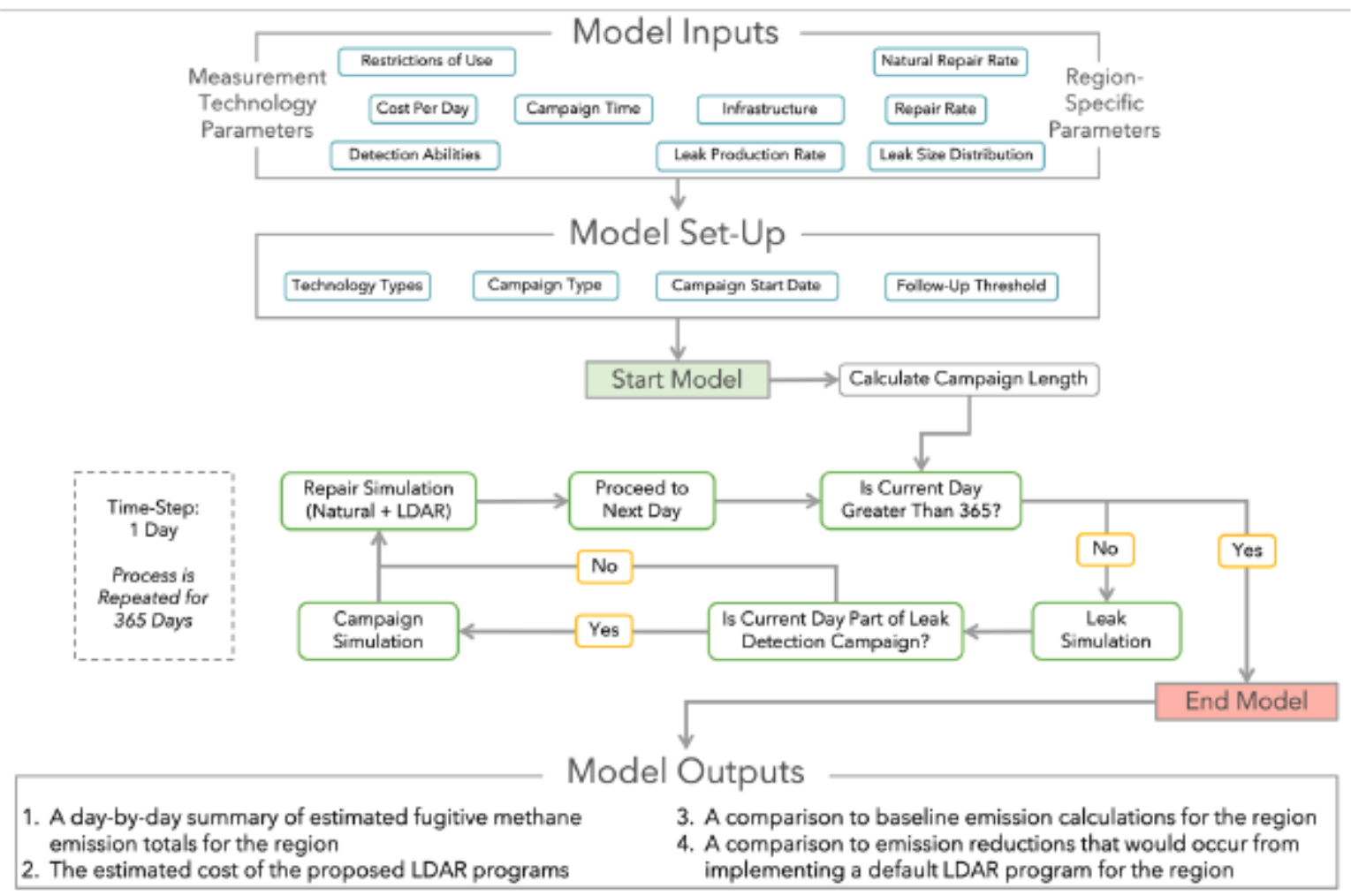

Figure 1: Flow-chart of model process.

Figure 2: Flow-chart of model process.

This paper is a non-peer reviewed preprint submitted to EarthArXiv 
The risk of the model results not reflecting reality increase for developments where routine LDAR programs have not been implemented, or in developments where Arolytics is not able to access emission datasets from similar regions / production styles.

Depending on the level of methane emission data available for each region to be modelled, assumptions may be made for various input parameters. Arolytics will disclose all assumptions to the producer in the final project report, and we encourage these assumptions to be additionally disclosed to the regulator upon the submission of an alternative LDAR program application.

It is also important to note that the model is continually being refined and the above process is subject to change. Any changes in process will be identified upon completion of the modeling work.

\section{S2.7 Confidentiality}

Arolytics understands the importance of being transparent about methods used to model alternative LDAR emission reductions. On reasonable request, Arolytics will disclose detailed descriptions of all processes used to acquire and analyze emission datasets, as well as the model algorithms. As a for-profit business, Arolytics reserves the right to withhold information about methods from parties who may be positioned as competitors to our products and services. The information contained in this document is confidential, privileged, and only for the intended recipient and may not be used, published or redistributed without the prior written consent of Arolytics Incorporated. 